\title{
ВЕДОМСТВЕННЫЙ КОНТРОЛЬ ДЕЯТЕЛЬНОСТИ ТАМОЖЕННЫХ ОРГАНОВ РФ В СОВРЕМЕННЫЙ ПЕРИОД
}

\begin{abstract}
Аннотация. Предметом исследования является ведомственный контроль деятельности таможенных органов РФ, его правовая регламентация, направления и сроки проведения, а также сравнительный анализ ведомственного и таможенного контроля. Обращено внимание на соотношение таможенного и ведомственного контроля как видов государственного контроля. Общим для них является субъект контроля, в качестве которого выступает таможенный орган. При этом объекты таможенного и ведомственного контроля, а также цели и последствия их реализации различаются. Кроме того в статье обозначено понятие вневедомственного (внешнего) контроля, который должен применяться в сочетании в ведомственный (внутренним) контролем. Методология исследования основана на анализе действующего таможенного законодательства, а также научной литературы в области таможенного регулирования. был также использованы исторический и сравнительно-правовой методы исследования. Основными выводами проведенного исследования являются положения о соотношении таможенного и ведомственного контроля, балансе ведомственного и вневедомственного контроля как основе обеспечения законности деятельности таможенных органов РФ.Особым вкладом автора в исследование темы является выделение общих свойств и различий таможенного и ведомственного контроля, а также вывод о том, соблюдение прав участников таможенных правоотношений возможно при оптимальном балансе ведомственного и вневедомственного контроля деятельности таможенных органов.
\end{abstract}

Ключевые слова: ведомственный контроль, таможенный контроль, таможенные органы, вневедомственный контроль, государственный контроль, объекты контроля, субъекты контроля, законность, таможенное законодательство, срок контроля.

Abstract. The research subject is internal control of the activities of customs bodies of the Russian Federation, its legal regulation, directions and time frame, and the comparative analysis of internal and customs control. The author pays attention to the correlation between customs and internal control as the forms of government control. The common element for the both forms of control is the subject of control represented by a customs body. At the same time, the objects of customs and internal control, their objectives and consequences are different. Moreover, the paper defines the notion of external control which should be applied together with the internal one. The research methodology is based on the analysis of the current customs legislation and the scientific literature in this field. The author applies historical and comparative-legal methods. The author formulates the provisions about the correlation between customs and internal control and the balance between them as a basis for ensuring legality in the work of customs bodies of the Russian Federation. The author outlines the common features and the peculiarities of customs and internal control and comes to the conclusion that the observance of rights of the participants of customs legal relations is possible given that the optimal balance between internal and external control of the activities of customs bodies is preserved.

Key words: control time frame, customs legislation, legality, subjects of control, objects of control, government control, external control, customs bodies, customs control, internal control.

$\mathrm{B}$ условиях административной реформы проблемы государственного контроля как вида социального контроля, принципов, порядка и механизмов его осуществления, обеспечения прав и законных интересов лиц при его реализации в современном обществе приобретают особую актуальность. Таможенный контроль является одним из видов государственного контроля. Исследование различных его аспектов и направлений в условиях международной экономической интеграции и активизации внешнеэкономической деятельности весьма востребовано. В то же время отдельные аспекты деятельности таможенных органов, напрямую связанные с реализацией ими таможенно- го и иных видов государственного контроля, в современных условиях остаются за рамками научных исследований. На наш взгляд, к ним следует отнести вопросы ведомственного контроля деятельности таможенных органов РФ.

Согласно статье 24 Федерального закона «0 таможенном регулировании в РФ» (далее - Закона) вышестоящий таможенный орган или вышестоящее должностное лицо таможенного органа в любое время в порядке ведомственного контроля вправе отменить или изменить не соответствующее требованиям таможенного законодательства Таможенного союза и законодательства Российской Федерации о таможенном деле решение ниже- 


\section{Административное и муниципальное право 5 (101) 2016}

стоящего таможенного органа или нижестоящего должностного лица таможенного органа в области таможенного дела, а также принять любые предусмотренные таможенным законодательством Таможенного союза и законодательством Российской Федерации о таможенном деле меры в отношении неправомерных действий (бездействия) нижестоящих таможенных органов или нижестоящих должностных лиц таможенных органов в области таможенного дела.

В случае, если после отмены (изменения) в порядке ведомственного контроля решения нижестоящего таможенного органа или нижестоящего должностного лица таможенного органа в области таможенного дела требуется принятие нового решения в области таможенного дела, такое решение принимается уполномоченным таможенным органом в соответствии с таможенным законодательством Таможенного союза и законодательством Российской Федерации о таможенном деле в сроки, установленные для проведения таможенного контроля [1].

Обратим внимание на то, что порядок проведения ведомственного контроля регламентирован на уровне законодательства РФ, в Таможенном кодексе Таможенного союза (далее - ТК ТС) данное понятие отсутствует.

Ведомственный контроль - сравнительно новый правовой институт, направленный на повышение уровня законности в деятельности таможенных органов РФ. Данное понятие впервые вводится законодателем в статье 412 Таможенного кодекса РФ 2003 года [2].

Согласно пп. а) пункта 2 Методических рекомендаций по проведению ведомственного контроля решений, действий (бездействия) в области таможенного дела ведомственный контроль - это деятельность таможенных органов, направленная на обеспечение соблюдения таможенного законодательства Таможенного союза и законодательства Российской Федерации о таможенном деле при принятии таможенными органами решений и совершении таможенными органами или должностными лицами таможенных органов действий (бездействия) при реализации ими задач и функций в области таможенного дела [3].

Таким образом, можно говорить о ведомственном контроле как своеобразном внутреннем контроле в структуре таможенного ведомства, что предполагает наличие и так называемого внешнего контроля, то есть контроля, осуществляемого иными государственными органами (например, органами прокуратуры) в отношении деятельности таможенных органов. В этой связи следует согласиться с мнением специалистов о том, что эффективное функционирование любой системы государственных органов возможно при наличии не только внутреннего, но и внешнего (вневедомственного) контроля.

Контроль как элемент управленческой деятельности, осуществляемый вышестоящими субъектами по отношению к нижестоящим, - ведомственный (внутренний) контроль. В этой части контрольные полномочия вышестоящих органов реализуются путем прямой отмены неправомерных или нерациональных решений нижестоящих органов и применения, в случае необходимости, мер дисциплинарной ответственности по отношению к лицам, виновным в совершении действий и решений, признанных ничтожными.

Однако в современных условиях ни одна система государственных органов не может оптимально функционировать при наличии лишь внутрисистемного контроля вышестоящих органов за исполнением законов нижестоящими, поэтому второй вид контроля включает более сложный механизм реализации, поскольку осуществляется государственными органами в отношении не подчиненных им организаций и лиц - вневедомственный (функциональный) внешний контроль. Он проводится субъектом, не входящим в одну систему с подконтрольным объектом [4].

Основными задачами ведомственного контроля деятельности таможенных органов РФ являются:

а) обеспечение соблюдения требований таможенного законодательства Таможенного союза и законодательства Российской Федерации о таможенном деле при принятии таможенными органами решений и совершении таможенными органами или должностными лицами таможенных органов действий (бездействия);

б) выявление и устранение нарушений таможенного законодательства Таможенного союза и законодательства Российской Федерации о таможенном деле, допущенных при принятии таможенными органами решений и совершении таможенными органами или должностными лицами таможенных органов действий (бездействия) в области таможенного дела;

в) восстановление прав и законных интересов государства и лиц, которые нарушены вследствие принятия не соответствующих требованиям таможенного законодательства Таможенного союза и законодательства Российской Федерации о таможенном деле решений или совершения неправомерных действий (бездействия) в области таможенного дела;

г) выявление причин и условий, способствующих принятию таможенными органами не соответствующих требованиям таможенного законодательства Таможенного союза и законодательства Российской Федерации о 
таможенном деле решений, совершению таможенными органами или должностными лицами таможенных органов неправомерных действий (бездействия) в области таможенного дела;

д) выработка мер, направленных на исключение фактов принятия нижестоящими таможенными органами повторных не соответствующих требованиям таможенного законодательства Таможенного союза и законодательства Российской Федерации о таможенном деле решений, совершения неправомерных действий (бездействия) в области таможенного дела [3]. При характеристике ведомственного контроля деятельности таможенных органов РФ закономерно возникает вопрос о периоде проведения подобного контроля. Несмотря на формулировку «в любое время» в тексте статьи 24 Закона период реализации ведомственного контроля имеет свои хронологические рамки.

Согласно позиции Пленума ВАС РФ по смыслу части 1 статьи 99 ТК ТС и части 2 статьи 164 Закона в отношении декларантов и иных заинтересованных лиц срок таможенного контроля, осуществляемого после выпуска товаров, ограничивается тремя годами со дня окончания нахождения товаров под таможенным контролем. Толкуя указанные нормы во взаимосвязи, судам необходимо иметь в виду, что и в том случае, когда основания для начисления сумм таможенных платежей, пеней, процентов возникли по итогам проведения ведомственного контроля, требование об уплате таможенных платежей (статья 152 Закона о таможенном регулировании) может быть направлено декларанту или иному заинтересованному лицу лишь в пределах трехлетнего срока, предусмотренного частью 2 статьи 164 Закона о таможенном регулировании. При этом названное требование может быть направлено соответствующему лицу не только тем таможенным органом, который осуществил выпуск товара, но и вышестоящим таможенным органом, проводившим ведомственный контроль [5].

Таким образом, в случае выставления плательщику требования об уплате таможенных пошлин, налогов по результатам осуществленного после выпуска товаров ведомственного контроля деятельности таможенных органов нужно учитывать, что такое требование может быть направлено декларанту в течение трех лет со дня окончания нахождения товаров под таможенным контролем. Именно этим сроком ограничивается период, в течение которого декларанту или иному заинтересованному лицу может быть направлено требование об уплате таможенных платежей - результат проведения ведомственного контроля [6].
Заслуживает внимания позиция авторов, которые справедливо разграничивают понятия «ведомственный контроль» и «таможенный контроль».

Так как ведомственный контроль может проводиться одновременно с таможенным контролем или вытекать из него, на практике особо важным и актуальным является разграничение данных видов контроля. Их анализ позволяет выявить существенные различия. Данные виды контроля имеют различные объекты контроля. В связи с этим таможенный контроль и ведомственный контроль имеют различные правовые цели и влекут различные правовые последствия [7].

Несмотря на то, что данные виды контроля могут проводиться таможенными органами и их должностными лицами одновременно, необходимо учитывать, что объектом ведомственного контроля являются решения таможенных органов, действия (бездействие) таможенных органов или должностных лиц таможенных органов, принятые и совершенные в области таможенного дела, а также решения, вынесенные по результатам ведомственного контроля. Что касается перечня объектов, в отношении которых проводится таможенный контроль, то он установлен действующим законодательством. Согласно п. 2 ст. 95 ТК ТС таможенный контроль проводится должностными лицами таможенных органов в отношении:

1) товаров, в том числе транспортных средств, перемещаемых через таможенную границу и (или) подлежащих декларированию в соответствии с ТК ТС;

2) таможенной декларации, документов и сведений о товарах, представление которых предусмотрено в соответствии с таможенным законодательством таможенного союза;

3) деятельности лиц, связанной с перемещением товаров через таможенную границу, оказанием услуг в сфере таможенного дела, а также осуществляемой в рамках отдельных таможенных процедур;

4) лиц, пересекающих таможенную границу [8].

Таким образом, следует дифференцировать таможенный контроль и ведомственный контроль, которые различаются по объектам, в отношении которых проводятся данные виды государственного контроля. В то же время общим для них является субъект контроля, в качестве которого в обоих случаях выступает таможенный орган.

Анализ отдельных нормативных актов и иных документов ФТС России позволяет выделить несколько направлений ведомственного контроля в зависимости от сегмента деятельности таможенных органов РФ. Например, ведомственный контроль за предоставлением уполномоченными должностными лицами регионального таможен- 


\section{Административное и муниципальное право 5 (101) 2016}

ного управления государственной услуги выдачи и отзыва квалификационных аттестатов. Так, согласно Административному регламенту Федеральной таможенной службы по предоставлению государственной услуги выдачи и отзыва квалификационных аттестатов специалистов по таможенным операциям ведомственный контроль за соблюдением и исполнением уполномоченными должностными лицами регионального таможенного управления положений Административного регламента, а также иных нормативных правовых актов, устанавливающих требования к предоставлению государственной услуги выдачи и отзыва квалификационных аттестатов, осуществляется ФТС России [9].

Другим примером является ведомственный контроль за деятельностью таможенных органов при осуществлении валютного контроля. Так, в рамках реализации цели и задач подпрограммы «Совершенствование таможенной деятельности» государственной программы Российской Федерации «Развитие внешнеэкономической деятельности» ФТС России планирует выполнение в среднесрочной перспективе целого ряда мероприятий, среди которых модернизация автоматизированного средства «Валютный контроль» в части организации возможности прикрепления электронных сканированных копий документов, на основании которых проведена проверка соблюдения участниками ВЭД валютного законодательства, и документов, подвергнутых анализу, к соответствующим полям электронной копии акта проверки в целях обеспечения надлежащего ведомственного контроля за деятельностью таможенных органов при осуществлении валютного контроля [10].

Еще одним направлением можно назвать ведомственный контроль в сфере закупок товаров, работ, услуг для обеспечения нужд таможенных органов и учреждений, находящихся в ведении ФТС России. В качестве одной из основных задач контрольно-ревизионного управления ФТС России является осуществление ведомственного контроля в сфере закупок товаров, работ, услуг для обеспечения нужд таможенных органов и учреждений, находящихся в ведении ФТС России [11].

Таможенные органы размещают информацию, касающуюся проведения ведомственного контроля. Так, по итогам проведения ведомственного контроля в отдельных случаях было установлено необоснованное применение форм таможенного контроля, а руководителю таможенного органа было поручено обеспечить принятие мер по устранению выявленных комиссией ФТС России нарушений законодательства РФ [12].

По мнению специалистов, в основном решения, вынесенные в результате проведенного ведомственного контроля, отменяют решения, связанные с контролем таможенной стоимости (решения о принятии заявленной таможенной стоимости товара, решения о корректировке заявленной таможенной стоимости товара, решения о самостоятельном определении таможенным органом таможенной стоимости товара) и классификацией товаров (решения о подтверждении заявленных декларантом сведений о коде товара в соответствии с ТН ВЭД, решения о классификации товаров в соответствии с ТН ВЭД) [13].

К основным целям ведомственного контроля относятся:

а) реализация государственной политики в области таможенного дела в части, касающейся соблюдения таможенного законодательства при перемещении товаров и транспортных средств через границу Российской Федерации, применении таможенных процедур, взимании таможенных платежей, совершении таможенных операций и проведении таможенного контроля, а также при применении запретов и ограничений, установленных в соответствии с законодательством Российской Федерации о государственном регулировании внешнеторговой деятельности;

б) защита прав и законных интересов государства, участников внешнеэкономической деятельности и лиц, осуществляющих деятельность в области таможенного дела;

в) изучение и обобщение практики деятельности таможенных органов в части соблюдения прав участников внешнеэкономической деятельности и на ее основе оказание своевременной правовой и методической помощи таможенным органам;

г) сокращение количества решений, действий (бездействия), принятых и совершенных в нарушение требований таможенного законодательства Таможенного союза и законодательства Российской Федерации о таможенном деле, а также устранение их вредных последствий;

д) сокращение количества судебных решений, принятых не в пользу таможенных органов [3].

Следует согласиться с мнением специалистов о том, что данный вид контроля представляет собой внутренний аудит деятельности таможенных органов. Следовательно, контрольные функции необходимо подразделять на внешние и внутренние. В основе данного разделения лежат объекты воздействия. Так, объектами воздействия при реализации внешних контрольных функций являются участники внешнеэкономической деятельности (лица, осуществляющие деятельность в области таможенного дела (таможенные перевозчики, таможенные брокеры, владельцы таможенных скла- 
дов), декларанты и другие лица, действующие в сфере таможенного дела). Правовой формой осуществления их деятельности является таможенный и валютный контроль. Объектом воздействия при осуществлении внутренних контрольных функций являются нижестоящие таможенные органы, их должностные лица. Правовой формой реализации данных функций выступает ведомственный контроль.

Данный контроль призван стать важным и необходимым направлением деятельности таможенных органов, реализация которого позволит сократить число незаконно принятых решений, действий (бездействия) таможенных органов и их должностных лиц, устранить их вредные последствия внутри системы таможенных органов, самостоятельно восстановить нарушенные права и законные интересы лиц, осуществляющих внешнеэкономическую деятельность [7].

Таким образом, можно сделать вывод о том, что таможенные органы наделены полномочиями по осуществлению таможенного, валютного, экспортного и иных видов государственного контроля. Особое место среди них занимает ведомственный контроль. Он появляется в практике таможенных органов РФ с 1 января 2004 года и развивается в условиях современного таможенного законодательства. Регламентация его осуществляется на национальном уровне.

Ведомственный контроль является одной из форм контроля соблюдения законности деятельности таможенных органов. Предоставленное законодателем право вышестоящего таможенного органа в любое время отменить или изменить не соответствующее требованиям законодательства решение нижестоящего таможенного органа или его должностного лица, способствует восстановлению прав и законных интересов заинтересованных лиц и государства, которые нарушены в результате принятия такого решения или совершения незаконных действий (бездействия) таможенными органами и их должностными лицами, сокращению числа таких решений и устранению их вредных последствий.

Следует разграничивать таможенный контроль и ведомственный контроль деятельности таможенных органов РФ. Они различаются объектами проведения контроля, а также целями и последствиями реализации. В то же время их объединяет единый субъект проведения: и таможенный, и ведомственный контроль осуществляются таможенными органами.

В зависимости от направления проверяемой деятельности таможенных органов РФ можно выделить различные направления проведения ведомственного контроля. Сроки проведения ведомственного контроля ограничены сроками осуществления таможенного контроля и составляют три года со дня окончания нахождения товаров под таможенным контролем.

В заключение отметим, что обеспечение соблюдения законности в деятельности таможенных органов возможно при оптимальном балансе ведомственного (внутреннего) контроля и вневедомственного (внешнего) контроля. Сочетание данных видов контроля позволит обеспечить права и законные интересы всех участников таможенных правоотношений.

\section{Библиография:}

1. Федеральный закон от 27.11.2010 N 311-Ф3 (ред. от 13.07.2015) "О таможенном регулировании в Российской Федерации" (с изм. и доп., вступ. в силу с 19.10.2015) СПС «КонсультантПлюс».

2. Таможенный кодекс Российской Федерации от 28 мая 2003 г. № 61-Ф3 (утратил силу). СПС «КонсультантПлюс».

3. Распоряжение ФТС России от 12.07.2011 N118-р (ред. от 04.12.2012) "Об утверждении Методических рекомендаций по проведению ведомственного контроля решений, действий (бездействия) в области таможенного дела". СПС «КонсультантПлюс».

4. Правовое регулирование государственного контроля: монография (отв. ред. д-р юрид. наук, проф., заслуженный деятель науки Российской Федерации А.Ф. Ноздрачев).-М.: "Институт законодательства и сравнительного правоведения при Правительстве РФ", 2013. СПС «Гарант».

5. Постановление Пленума ВАС РФ от 08.11.2013 N 79 "О некоторых вопросах применения таможенного законодательства" // "Вестник ВАС РФ", N 1, январь, 2014.

6. Столяров Д.А., Применение таможенного законодательства // Промышленность: бухгалтерский учет и налогообложение. 2014. № 1. СПС «Гарант».

7. Трунина Е.В. Контрольные функции таможенных органов: виды, правовое регулирование, практика реализации // Право и экономика. 2009. № 6. СПС «Гарант».

8. Таможенный кодекс Таможенного союза (ред. от 08.05.2015)(приложение к Договору о Таможенном кодексе Таможенного союза, принятому Решением Межгосударственного Совета ЕврАзЭС на уровне глав государств от 27.11.2009 N 17). СПС «КонсультантПлюс».

9. Приказ ФТС России от 08.11.2011 N 2263 (ред. от 26.09.2014) "Об утверждении Административного регламента Федеральной таможенной службы по предоставлению государственной услуги выдачи и отзыва квалификационных аттестатов специалистов по таможенным операциям" (Зарегистрировано в Минюсте России 22.02 .2012 N 23315). СПС «КонсультантПлюс». 
10. Итоговый доклад о результатах и основных направлениях деятельности Федеральной таможенной службы на 2015 год и плановый период 2016 - 2018 годов. Официальный сайт ФТС России. Электронный pecypc. http:// customs.ru/index.php?option=com_content\&view=article\&id=20613:-2015-2016-2018-\&catid=475:2015-03-12-0957-15\&Itemid=2588 (дата обр. 24.12.2015).

11. Структура центрального аппарата ФТС России. Официальный сайт ФТС России. Электронный pecypc. http://www. customs.ru/index.php?option=com_content\&view=article\&id=39\%3A2011-01-12-20-24-55\&catid=12\&Itemid=1822 (дата обр. 24.12.2015).

12. Комментарий к Федеральному закону от 27 ноября 2010 г. N 311-Ф3 "О таможенном регулировании в Российской Федерации" (постатейный) (под ред. С.А. Овсянникова, Г.Н. Комковой) (Подготовлен для системы КонсультантПлюс, 2012).

13. Рыжова М.А. Ведомственный контроль деятельности таможенных органов как способ обеспечения законности в области таможенного дела / Вестник Российской таможенной академии. 2014. № 1. - С. 127.

\section{References (transliterated):}

1. $\quad$ Federal'nyi zakon ot 27.11.2010 N 311-FZ (red. ot 13.07.2015) "O tamozhennom regulirovanii v Rossiiskoi Federatsii" (s izm. i dop., vstup. v silu s 19.10.2015) SPS «Konsul'tantPlyus».

2. Tamozhennyi kodeks Rossiiskoi Federatsii ot 28 maya 2003 g. № 61-FZ (utratil silu). SPS «Konsul'tantPlyus».

3. Rasporyazhenie FTS Rossii ot 12.07.2011 N118-r (red. ot 04.12.2012) "Ob utverzhdenii Metodicheskikh rekomendatsii po provedeniyu vedomstvennogo kontrolya reshenii, deistvii (bezdeistviya) v oblasti tamozhennogo dela". SPS «Konsul'tantPlyus».

4. Pravovoe regulirovanie gosudarstvennogo kontrolya: monografiya (otv. red. d-r yurid. nauk, prof., zasluzhennyi deyatel' nauki Rossiiskoi Federatsii A.F. Nozdrachev).-M.: "Institut zakonodatel'stva i sravnitel'nogo pravovedeniya pri Pravitel'stve RF", 2013. SPS «Garant».

5. PostanovleniePlenumaVASRFot08.11.2013N79"Onekotorykhvoprosakhprimeneniyatamozhennogozakonodatel'stva"// "Vestnik VAS RF", N 1, yanvar', 2014.

6. Stolyarov D.A., Primenenie tamozhennogo zakonodatel'stva // Promyshlennost': bukhgalterskii uchet i nalogooblozhenie. 2014. № 1. SPS «Garant».

7. Trunina E.V. Kontrol'nye funktsii tamozhennykh organov: vidy, pravovoe regulirovanie, praktika realizatsii // Pravo i ekonomika. 2009. № 6. SPS «Garant».

8. Tamozhennyi kodeks Tamozhennogo soyuza (red. ot 08.05.2015)(prilozhenie k Dogovoru o Tamozhennom kodekse Tamozhennogo soyuza, prinyatomu Resheniem Mezhgosudarstvennogo Soveta EvrAzES na urovne glav gosudarstv ot 27.11.2009 N 17). SPS «Konsul'tantPlyus».

9. Prikaz FTS Rossii ot 08.11.2011 N 2263 (red. ot 26.09.2014) "Ob utverzhdenii Administrativnogo reglamenta Federal'noi tamozhennoi sluzhby po predostavleniyu gosudarstvennoi uslugi vydachi i otzyva kvalifikatsionnykh attestatov spetsialistov po tamozhennym operatsiyam" (Zaregistrirovano v Minyuste Rossii 22.02.2012 N 23315). SPS «Konsul'tantPlyus».

10. Itogovyi doklad o rezul'tatakh i osnovnykh napravleniyakh deyatel'nosti Federal'noi tamozhennoi sluzhby na 2015 god i planovyi period 2016 - 2018 godov. Ofitsial'nyi sait FTS Rossii. Elektronnyi resurs. http://customs.ru/index. php?option=com_content\&view=article \&id=20613:-2015-2016-2018-\&catid=475:2015-03-12-09-57-15\&Itemid=2588 (data obr. 24.12.2015).

11. Struktura tsentral'nogo apparata FTS Rossii. Ofitsial'nyi sait FTS Rossii. Elektronnyi resurs. http://www.customs.ru/ index.php?option=com_content\&view=article\&id=39\%3A2011-01-12-20-24-55\&catid=12\&Itemid=1822 (data obr. 24.12.2015).

12. Kommentarii k Federal'nomu zakonu ot 27 noyabrya 2010 g. N 311-FZ "O tamozhennom regulirovanii v Rossiiskoi Federatsii" (postateinyi) (pod red. S.A. Ovsyannikova, G.N. Komkovoi) (Podgotovlen dlya sistemy Konsul'tantPlyus, 2012).

13. Ryzhova M.A. Vedomstvennyi kontrol' deyatel'nosti tamozhennykh organov kak sposob obespecheniya zakonnosti $\mathrm{v}$ oblasti tamozhennogo dela / Vestnik Rossiiskoi tamozhennoi akademii. 2014. № 1. - S. 127. 